\title{
Reflexões sobre a formação inicial de professores de Português como Língua Estrangeira/Segunda Língua (PLE/PL2) na Universidade Federal da Bahia em uma perspectiva culturalmente sensível
}

\author{
Sara Oliveira da Cruz* \\ Resumo
}

Este trabalho é parte de uma pesquisa maior que teve como objetivo propor o blog como um ambiente favorável ao ensino de Português como Língua Estrangeira/Segunda Língua (PLE/PL2) em uma perspectiva culturalmente sensível aos sujeitos envolvidos no processo de ensino-aprendizagem de línguas (CRUZ, 2019). A extensão universitária e os projetos institucionais da Universidade Federal da Bahia (UFBA), respectivamente o Núcleo Permanente de Extensão em Letras (NUPEL) e o Programa Especial de Monitoria de Português como Língua Estrangeira (PROEMPLE), são os contextos dessa investigação. Aqui, se discute a formação de professores(as) de PLE/PL2, em nível de graduação, na UFBA, e a sua ancoragem em princípios voltados para uma formação culturalmente sensível de seus(suas) professores(as) (MENDES, 2020), a fim de evidenciar a importância de uma orientação teórico-pedagógica mais ativa, simétrica (e mais significativa) para os(as) professores(as) em formação, capaz de formar profissionais crítico-reflexivos (e culturalmente sensíveis), como foi defendido na referida pesquisa.

Palavras-chave: Português Língua Estrangeira/Segunda Língua (PLE/PL2). Formação de professores. Perspectiva intercultural. Universidade Federal da Bahia.

\footnotetext{
Instituto Federal de Educação, Ciência e Tecnologia da Bahia (IFBA). Graduada em Letras Vernáculas e Português como Língua Estrangeira. Especialista em Educação a Distância. Mestra em Língua e Cultura pela Universidade Federal da Bahia. Professora substituta de Língua Portuguesa. Pesquisadora no Núcleo de Estudos em Língua, Cultura e Ensino (Lince/CNPQ) e no Observatório de Português Língua Estrangeira/Segunda Língua (ObsPLE-PL2, CNPQ). Atua, desde 2012, no Exame de Certificação de Proficiência em Língua Portuguesa para Estrangeiros (Celpe-Bras). Orcid: https://orcid.org/0000-0001-98861762.
} 


\section{Reflexiones sobre la formación inicial de profesores de Portugués como Lengua Extranjera/ Segunda Lengua (PLE/PL2) en la Universidade Federal da Bahia - Brasil en una perspectiva culturalmente sensible}

\section{Resumen}

Este trabajo es parte de una investigación mayor que tuvo como objetivo proponer el blog como un ambiente favorable a la enseñanza de Portugués como Lengua extranjera/ Segunda Lengua (PLE/PL2) en una perspectiva culturalmente sensible a los sujetos involucrados en el proceso de enseñanza- aprendizaje de lenguas (CRUZ, 2019). La extensión universitaria y los proyectos institucionales de la Universidade Federal da Bahia (UFBA), respectivamente el Núcleo Permanente de Extensión en Letras (NUPEL) y el Programa Especial de Monitoria de Portugués como Lengua Extranjera (PROEMPLE), son los contextos de esa investigación. Aquí, discuto la formación de profesores(as) de PLE/PL2, en nivel de graduación, en UFBA y su anclaje en principios vueltos para una formación culturalmente sensible de sus profesores(as) (MENDES, 2020), con el propósito de evidenciar la importancia de una orientación teórico- pedagógica más activa, simétrica (y más significativa) para Las(os) profesores(as) en formación, capaz de formar profesores críticos- reflexivos (y culturalmente sensibles), como fue definido en la pesquisa.

Palabras-clave: Portugués Lengua Extranjera/Segunda Lengua (PLE/PL2). Formación de Profesores. Perspectiva intercultural. Universidade Federal da Bahia (UFBA).

Recebido em: 04/03/2021 // Aceito em: 11/04/2021. 


\section{Introdução ${ }^{1}$}

As ideias desenvolvidas dentro da Linguística Aplicada sobre a formação de professores de línguas, sobretudo os trabalhos de Mendes (2008; 2011; 2012a; 2012b; 2014), apontam diferentes aspectos relativos ao desenvolvimento de abordagens e práticas mais sensíveis culturalmente, que colocam os sujeitos em interação como foco do ensino e da aprendizagem de uma nova língua-cultura. ${ }^{2}$ Nesse sentido, a autora defende uma formação em nível superior que prepare o(a) professor(a) de Português Língua Estrangeira/Segunda Língua (PLE/PL2) para atuar em contextos complexos e multilíngues, marcados pela diversidade, pela desigualdade e, muitas vezes, pela injustiça social, assim como para decidir, com autonomia e consciência crítica, que representações de língua e de linguagem estarão na base de suas ações.

$\mathrm{Na}$ perspectiva da educação interculturalmente sensível (MENDES, 2011), isso é um grande desafio, visto que, tradicionalmente, ainda imperam, nos Cursos de Licenciatura em Letras, abordagens e práticas que perpetuam concepções e visões clássicas de língua, nas quais o ensino da gramática ocupa lugar central. De base estruturalista, essas concepções e visões de língua nos impedem de pensá-la como uma prática social, uma atividade, uma ação desempenhada pelos sujeitos que interagem através dela, que considera não apenas sua dimensão linguística, mas também as dimensões sociocultural, histórica e política.

\footnotetext{
1 Agradeço aos meus/minhas colegas de pós-graduação pela leitura atenta deste artigo: Helitânia dos Santos, Remígio Pires, Lucas Rodrigues, e à Iris Nunes, que sempre me auxilia na produção do resumo em língua estrangeira. Nesses tempos de isolamento social, essa troca tem sido fundamental.

2 Mendes (2008, p. 72) denomina língua-cultura como uma "rede complexa de fatores linguísticos e extralinguísticos. [...] não é uma abstração teórica e não possui existência fora do contexto social de uso pelos seus falantes." Para a autora, "além do conhecimento relativo à língua que está sendo ensinada e aprendida", professores e aprendizes "devem poder compartilhar na sala de aula [...] toda uma rede de conhecimentos e informações que fazem parte dos seus mundos culturais específicos". (MENDES, 2012a, p. 362).
} 
Em poucas linhas, o sentido de sensível a que Mendes se refere em seus escritos é essa ação de criar espaços propícios para o diálogo e para a troca de experiências das línguas-culturas dos sujeitos em interação, como também de procurar imprimir, nos cursos de formação de professores de línguas, a diversidade e a complexidade do mundo contemporâneo. Atuar em uma perspectiva culturalmente sensível aos sujeitos envolvidos no processo de ensino-aprendizagem de línguas é oportunizar o diálogo intercultural entre as línguas-culturas em contato. ${ }^{3}$ Essa tem se revelado uma das principais tendências contemporâneas de ensino de línguas capaz de "suscitar comportamentos e atitudes comprometidos com princípios orientados para o respeito ao outro, às diferenças, à diversidade cultural que caracteriza todo o processo de ensino-aprendizagem" de línguas. (MENDES, 2012a, p. 359-360). Sobre a significação da palavra intercultural, a autora afirma que:

O sentido de intercultural [...] é a compreensão de que é possível, no emaranhado das diferenças e choques culturais que estão em jogo no mundo contemporâneo, estabelecer pontes, diálogos inter/entre culturas, individuais e coletivas, de modo que possamos conviver mais respeitosamente, mais democraticamente [...] é o de um esforço, uma ação integradora, capaz de suscitar comportamentos e atitudes comprometidos com princípios orientados para o respeito ao outro, às diferenças, à diversidade cultural que caracteriza todo o processo de ensino-aprendizagem, seja ele de línguas ou de qualquer outro conteúdo escolar. (MENDES, 2012a, p. 359-360).

Nessa perspectiva, Egito (2019, p. 22), referenciando Kramsch, nos diz que uma educação intercultural deve se basear

3 Mendes (2020, p. 53) vem nos dizer que "dialogar dentro da interculturalidade significa, portanto, abrir-se para a outra cultura e deixar-se ver pelo outro com o qual se estabelece o diálogo". 
"no respeito à diferença e na aceitação do Outro e de seu modo de ver, agir e sentir o mundo". Seguindo o mesmo pensamento, Candau acredita que se trata de:

[...] uma educação para o reconhecimento do 'outro', para o diálogo entre os diferentes grupos sociais e culturais. Uma educação para a negociação cultural, que enfrenta conflitos provocados pela assimetria de poder entre os diferentes grupos socioculturais nas nossas sociedades e é capaz de favorecer a construção de um projeto comum, pelo qual as diferenças sejam dialeticamente integradas [...]. (CANDAU, 2008, p. $52)$.

Sendo assim, o(a) professor(a) de PLE/PL2 que se pretende intercultural precisa compreender que conflitos, embates, choques, silenciamentos são atitudes que surgem nas relações humanas, no entanto, é preciso aprender a construir a ponte entre as línguas-culturas em contato, a ser sensível culturalmente na escuta do outro e na escuta de si mesmo e compreender que, por meio da linguagem, ferimos e somos feridos.

Dito isso, a formação de professores(as) de Português como Língua Estrangeira/Segunda Língua da UFBA passou, nos últimos anos, por algumas transformações, principalmente na organização curricular e nos conteúdos do Curso de Licenciatura em PLE dessa instituição.

De 2005, ano em que foi criada, a 2011, tratava-se de uma formação em dupla habilitação, com o objetivo de preparar o egresso para o ensino de língua materna e também de língua estrangeira (Licenciatura em Letras Vernáculas e Língua Estrangeira Moderna - Português Língua Estrangeira). ${ }^{4}$ Em 2012, após determinação imposta pela Resolução CNE/ $\mathrm{CP} \mathrm{n}^{\mathrm{o}} 1 / 2011$, que previa um aumento da carga horária das 
Licenciaturas em Letras com dupla habilitação para o mínimo de 3.600 horas, a Comissão de Reforma Curricular decidiu pela extinção das habilitações duplas, e o curso foi totalmente reformulado, passando a ser uma Licenciatura em Língua Estrangeira - Português Língua Estrangeira/Segunda Língua (MENDES, 2020). ${ }^{5}$

Na nova formulação do Projeto do Curso, de acordo com Mendes:

Grande ênfase é dada no curso à preparação do professor para desenvolver um corpo de conhecimentos que inclua não apenas o domínio dos conteúdos específicos da língua, objeto de seu ensino, mas também uma formação crítica e ancorada na compreensão da diversidade e da necessidade de desenvolvimento de práticas educacionais culturalmente sensíveis aos sujeitos envolvidos no processo de ensino e aprendizagem. Além disso, o professor deve ser preparado para atuar, antes de tudo, como um agente de interculturalidade, bem como agente político de promoção e de projeção da língua portuguesa no mundo. (MENDES, 2020, p. 45).

Com isso, vemos a instituição assumir a responsabilidade de preparar professores(as) de PLE/PL2 capazes de formar cidadãos plurilíngues e interculturais, sabedores das concepções, das crenças, das abordagens que orientam a prática pedagógica, a seleção e a produção de materiais didáticos e de instrumentos de avaliação, entre outros elementos que compõem o processo de ensinar e aprender uma língua, bem como capazes de analisar, avaliar e intervir em situações complexas, em salas de aula de línguas multiculturais e, muitas vezes, conflituosas, com autonomia e consciência crítica. (MENDES, 2014, p. 36).

5 Para saber mais sobre a reformulação do Projeto do Curso e o desenvolvimento do PLE/PL2 na Universidade Federal da Bahia (UFBA), especialmente a licenciatura na área, iniciada no ano de 2005, ver Mendes (2020). 
Como esse novo currículo ainda está em fase de implementação, não apresento o seu impacto na formação desses(as) professores(as), visto que se faz necessário o desenvolvimento de pesquisas que investiguem, sobretudo, de que modo essa implementação está ocorrendo e quais as implicações na formação desses(as) profissionais. No entanto, a fim de contribuir com as reflexões acerca desse período de implementação do novo currículo, neste trabalho, apresentase um recorte dos dados gerados em uma pesquisa, em nível de mestrado, que teve como objetivo propor o blog como um ambiente favorável ao ensino de Português como Língua Estrangeira/Segunda Língua (PLE/PL2), em uma perspectiva culturalmente sensível aos sujeitos envolvidos no processo de ensino-aprendizagem de línguas (CRUZ, 2019). Esses dados apontaram para lacunas no processo de formação desses(as) professores(as), devido à assimetria que existe em relação às diferentes tendências formativas no interior do curso, sendo este um desafio profissional (MENDES, 2014, p. 36-37) que a instituição pode estar enfrentando na implementação desse novo currículo. 6

$\mathrm{Na}$ próxima seção, apresenta-se o percurso teóricometodológico dessa pesquisa. Antes, é importante dizer que se investigaram, inicialmente, as potencialidades do blog no ensino de PLE/PL2, tomando como contexto de investigação a extensão universitária e os projetos institucionais da Universidade Federal da Bahia (UFBA), respectivamente o Núcleo Permanente de

\footnotetext{
6 Segundo Mendes (2014), são quatro os desafios (conhecimento, profissional, social e político) enfrentados pelas instituições, públicas e privadas, no desenvolvimento de cursos e na formação de novos(as) professores(as) de PLE/PL2, tanto na fase inicial formativa, a exemplo dos cursos de licenciatura, quanto na capacitação dos professores em serviço. Para enfrentar o desafio profissional, a autora explica que "as instituições devem desenvolver condições para preparar, em estágios iniciais e continuadamente, professores de línguas capazes de formar cidadãos plurilíngues e interculturais", ainda, "é necessário formar sujeitos para analisar, avaliar e intervir em situações complexas, em salas de aula de línguas multiculturais e, muitas vezes, conflituosas". (MENDES, 2014, p. 36).
} 
Extensão em Letras (NUPEL) e o Programa Especial de Monitoria de Português como Língua Estrangeira (PROEMPLE), mas, à medida que a investigação avançava, percebeu-se a necessidade de redimensionar os objetivos, de modo a incluir um olhar mais aprofundado sobre o próprio funcionamento desses projetos e os modos como os(as) professores(as) em formação de PLE/ PL2, em nível de graduação, estavam sendo formados(as) e orientados(as) em sua prática. ${ }^{7}$

\section{Percurso teórico-metodológico da pesquisa}

O conjunto de práticas metodológicas (DENZIN; LINCOLN, 2006, p. 20-22) adotado, nesta investigação, revela-se como qualitativo, de cunho etnográfico, com recortes autoetnográficos, porque incide nela a análise do fenômeno em tela para que este seja apreendido em sua complexidade, buscando interpretar as subjetividades dos participantes (PESCE; ABREU, 2013, p. 22), valendo-se de instrumentos e procedimentos etnográficos, que a aproximam do cenário e dos participantes da pesquisa (DENZIN; LINCOLN, 2006, p. 20-22). Nesse sentido, elaboro perguntas de pesquisa, não hipóteses, baseadas, inicialmente, em minha práxis docente e minhas leituras sobre a temática (BORTONI-RICARDO, 2008, p. 50). ${ }^{8}$ Além disso,

7 A extensão universitária e os projetos institucionais são os dois campos de atuação em que os estudantes da Licenciatura em PLE realizam as 408 horas de estágio do curso. Ver Rodrigues (2019), Cruz (2019) e Mendes (2020). O NUPEL é o órgão responsável pela coordenação, fomento, gerenciamento, apoio, acompanhamento e avaliação de ações de extensão do Instituto de Letras da UFBA. (NUPEL, 2021). Nesse espaço, estudantes da graduação e da pós-graduação podem exercer a docência de seu estágio obrigatório nas diferentes línguas oferecidas pelo Núcleo: alemão, espanhol, francês, grego, inglês, italiano, latim, LIBRAS e português língua estrangeira/segunda língua. Já o PROEMPLE é um subprograma do Programa de Proficiência em Língua Estrangeira para Estudantes e Servidores da UFBA (PROFICI). O PROFICI conta, atualmente, com seis subprogramas: PROEMA (alemão), PROEMES (espanhol), PROEMF (francês), PROEMI (inglês), PROEMIT (italiano), PROEMPLE (português como língua estrangeira). (PROFICI, 2021). Esse tem sido também um espaço para os professores em formação do Curso de Licenciatura em PLE da UFBA atuarem como monitores docentes nas turmas formadas pelo programa ou como tutores dos estudantes de PLE do programa.

8 A fenomenologia é uma das bases filosóficas da pesquisa qualitativa e, diferentemente das pesquisas positivistas, "não lida 
em um primeiro momento, analiso registros do início da minha atuação docente, como professora em formação no NUPEL, a fim de identificar quais concepções de língua orientaram a minha prática e de que forma utilizei o blog "Vivendo no Brasil" durante aquela experiência. Esses registros que emergem como recortes autoetnográficos demonstram a reflexividade no objeto pesquisado. ${ }^{9}$

Entre 2017 e 2019, período em que foi realizada a pesquisa, o NUPEL contava com dois professores(as) em formação e uma coordenadora. As aulas eram ministradas por estudantes da graduação e da pós-graduação stricto sensu do Instituto de Letras, aprovados(as) através de edital. $\mathrm{O}(\mathrm{A})$ estudante selecionado(a) poderia permanecer no Núcleo durante o tempo máximo de quatro semestres, período de duração da bolsa concedida. Já o PROEMPLE contava com três professores(as) em formação e um coordenador. As aulas eram ministradas por estudantes regularmente matriculados(as) em cursos de graduação ou pósgraduação stricto sensu da área de Letras, que já tinham feito a disciplina LETB12 - Introdução ao ensino do Português como Língua Estrangeira e aprovados(as) através de edital, além dos(as) estudantes da licenciatura em PLE/PL2 do Instituto de Letras da UFBA (ILUFBA) que estavam realizando os estágios supervisionados. ${ }^{10}$

com o conceito de hipóteses (que devem ser verificadas), mas sim com o conceito de suposições (que devem ser respondidas, com base na análise dos relatos dos sujeitos)". (PESCE e ABREU, 2013, p. 23). Entretanto, isso não é característico apenas da fenomenologia, mas de toda pesquisa qualitativa em essência.

9 Considero registros os e-mails trocados com os meus ex-alunos, um artigo apresentado em um dos congressos internacionais da SIPLE, produções escritas dos meus ex-alunos e o blog "Vivendo no Brasil" (http://vivendonobrasil.blogspot.com/). Atuei no NUPEL por três semestres, durante essa experiência, tive a ideia de criar esse blog para compartilhar as produções escritas dos meus alunos. A proposta da atividade consistia em produzir um texto sobre a temática abordada em aula para publicar nesse blog, em seguida, ler as postagens e comentar nesse ambiente virtual.

10 LETB 12 - Introdução ao Ensino do Português como Língua Estrangeira é um componente introdutório da Licenciatura em Português Língua Estrangeira/Segunda Língua na UFBA. Esse é um dos componentes dessa licenciatura voltado, segundo MENDES (2020, p.56), “especificamente para o processo de ensino e de aprendizagem do Português como Língua Estrangeira (Introdução ao Ensino do Português como Língua Estrangeira, Leitura e Produção de Textos em Português como Língua Estrangeira, Oralidade em Português como Língua Estrangeira, Análise Linguística em Português como Língua Estrangeira e 
No total, oito professores(as) em formação de PLE participaram desta pesquisa, sendo dois do NUPEL, um monitor e cinco tutores do PROEMPLE. Para preservar a identidade deles(as), optei por nomeá-los(as) com os nomes dos países ou continentes correspondentes à origem da maior parte dos seus alunos, a saber: Benim, Gabão, Gana, República Democrática do Congo, Haiti, África, América, Europa.

Os dados foram gerados a partir das observações de aulas e das entrevistas realizadas com todos(as) os(as) participantes; da implementação do conjunto de atividades; e também dos relatórios de estágio dos(as) professores(as) em formação que estavam cursando a disciplina Estágio Supervisionado I de Português como Língua Estrangeira, componente curricular do Curso de Licenciatura em PLE da UFBA. Analisei também, como disse anteriormente, registros do início da minha atuação docente, como professora em formação no NUPEL, a fim de identificar de que modo minhas próprias experiências foram ressignificadas a partir do desenvolvimento da investigação.

Essas observações foram necessárias para o desenvolvimento do conjunto de atividades proposto na pesquisa, bem como para a elaboração dos roteiros das entrevistas semiestruturadas. ${ }^{11}$ As anotações no diário de campo foram fundamentais para que eu pudesse refletir sobre as interações que ali ocorriam (ou não), sobre as falas e as ações dos(as) professores(as) em formação e dos(as) seus(suas) alunos(as) e também descrever/relatar as atividades conforme estavam acontecendo. Quanto aos relatórios de estágio, foram utilizados com vistas a gerar dados para compreender o fenômeno investigado por outro ângulo, seja complementando as análises

\footnotetext{
Avaliação de Proficiência em Português como Língua Estrangeira, com 68 horas cada um, totalizando 340 horas)”.

11 O conjunto de atividades foi dividido em três Unidades Temáticas: "Como é a sua Rotina", "Preconceito" e "Racismo", que resultaram das observações de aulas dos professores em formação participantes da pesquisa e de produções textuais de alunos de língua estrangeira.
} 
do diário de campo e das entrevistas, seja trazendo aspectos importantes que, por alguma razão, não foram mencionados nos outros instrumentos.

Com os dados, refleti, em especial, sobre o planejamento realizado pelos(as) professores(as) em formação; a(s) abordagem(ns) utilizada(s) por eles(as); as orientações que recebem no NUPEL, no PROEMPLE e durante o Estágio Supervisionado I de Português como Língua Estrangeira; ${ }^{12}$ os desafios na formação desses professores; a não oferta pelo ILUFBA de uma disciplina voltada para o uso de tecnologias digitais no ensino de línguas, sobretudo, na área de PLE; a implementação do conjunto de atividades e o uso do blog em uma perspectiva intercultural e crítica. ${ }^{13}$

Na seção seguinte, apresenta-se o recorte dos dados gerados na referida pesquisa, o qual evidencia a assimetria que existe em relação às diferentes tendências formativas no interior do curso, com vistas a discutir o compromisso, assumido por essa Universidade, de formar professores(as) crítico-reflexivos(as) (e culturalmente sensíveis).

\section{O compromisso de formar professores(as) crítico- reflexivos(as) (e culturalmente sensíveis) versus a ausência de uma orientação teórico-pedagógica mais ativa, simétrica (e significativa)}

Diante do propósito de ofertar uma formação que prepare os(as) professores(as) de PLE/PL2 para enfrentar os desafios

\footnotetext{
12 No decorrer do curso, os estudantes dessa licenciatura fazem quatro disciplinas de Estágio Supervisionado, totalizando 408 horas de estágio, a saber: Estágio Supervisionado I de Português como Língua Estrangeira; Estágio Supervisionado II de Português como Língua Estrangeira; Estágio Supervisionado III de Português como Língua Estrangeira, e Estágio Supervisionados IV de Português como Língua Estrangeira. Mendes (2020) discorre sobre a estrutura da licenciatura em PLE/PL2 na UFBA.

13 No total, dois blogs foram utilizados na investigação: "Vivendo no Brasil" (www.vivendonobrasil.blogspot.com) e "Falando Português" (www.falandoportugues.com.br).
} 
dos contextos diversificados, linguísticos e culturais, cabe, neste trabalho, refletir sobre a formação de professores de PLE/PL2 na UFBA. Os dados gerados na pesquisa revelaram que a ausência de uma orientação teórico-pedagógica mais ativa, simétrica (e mais significativa) em contextos formativos pode levar os(as) professores(as) em formação a não ressignificarem a própria prática, a não refletirem sobre as concepções de língua, de ensino, de avaliação que orientam a sua prática. Assim, a ausência desse tipo de orientação pode comprometer significativamente todo o processo formativo desses sujeitos em formação.

Vejamos o que América comenta, no Excerto [1], sobre como tem sido a sua experiência no NUPEL:

Excerto [1]

América: Minha experiência no NUPEL tem sido satisfatória. O primeiro semestre posso dizer que foi um semestre de teste, foi um semestre que eu apliquei tudo aquilo que eu tinha vontade e vi de que forma isso foi recebido. $\mathrm{O}$ segundo semestre tem sido um semestre mais desafiador por conta de ser uma turma com nível diferente do que eu tava acostumado a trabalhar, mas ao mesmo tempo tá sendo um semestre proveitoso porque tudo que eu tô fazendo agora é algo que eu não tinha feito antes, então, mais uma vez tá sendo desafiador e novo. (Entrevista - Professor em formação do NUPEL).

Em sua fala, ele apresenta uma situação bem parecida com a minha atuação no NUPEL. Para mim, essa também foi uma experiência satisfatória, proveitosa, desafiadora e nova. $\mathrm{Na}$ minha transição do primeiro para o segundo semestre, também passei a atuar em níveis superiores (intermediário e avançado) e tive o insight de utilizar um blog nas aulas, assim como ela, passei a fazer coisas que não havia feito anteriormente.

No próximo Excerto [2], observa-se que a fala de Europa é 
marcada pelo uso da primeira pessoa do singular "eu aprimorava", “eu via”, “(eu) tentava adaptar”, “eu tentava mudar”, assim como a de América, no Excerto [1], “eu apliquei”, "tudo que eu tô fazendo [...] é algo que eu não tinha feito [...]":

Excerto [2]

Europa: [...] Então, por exemplo, no primeiro semestre, eu fiquei, acho que foi no primeiro ou segundo que eu fiquei com o básico 1 e 2 , depois eu passei pro intermediário e pro avançado; mas, aí, a cada segundo semestre que eu dava a mesma disciplina, que eu dava o mesmo nível, eu aprimorava algumas coisas, né, e eu via o que que foi que deu certo, que deu errado e, aí, tentava adaptar, embora o perfil do aluno influencia muito nessa questão. Então, tem alunos que são mais sérios, não preferem alguns tipos de atividades, outro sim; alguns são mais críticos, outros não, né.

Pesquisadora: E como é que você desenrolava isso?

Europa: Ah, dependia deles, dependia deles sempre. $\mathrm{Na}$ verdade, as questões que eles gostavam mais, a gente tendia a demorar mais duas aulas, por exemplo, a gente demorava duas aulas num assunto se fosse o caso, mas se não fosse um assunto que demandasse muita informação, porque a partir de um conteúdo, a gente pode introduzir mais dois, três, aí que tá a riqueza, mas quando a gente via, que eu via que um tema não era muito rentável, eu tentava mudar logo pra poder chamar atenção deles. (Entrevista - Professora em formação do NUPEL).

O uso da primeira pessoa do singular na fala de Europa somado à minha reflexão sobre a minha atuação como professora em formação no NUPEL podem revelar o protagonismo que esses professores exercem no Núcleo e a ausência de uma orientação mais ativa nesse espaço. ${ }^{14}$

14 Ver capítulo da Dissertação (CRUZ, 2019) cujo título é "Da prática à teoria: uma experiência de ensino de português LE/L2 que se transformou em um projeto de pesquisa". 
Tendo em vista o que foi apresentado nos Excertos [1] e [2], considero que atuar nos níveis básicos (1 e 2), em uma perspectiva que limita "o ensino de línguas a uma mera exposição de conceitos, estruturas e regras, para depois aplicálos em situações superficiais e descontextualizadas" (MENDES, 2020, p. 49), é uma zona de conforto para o professor em formação, visto que há grande possibilidade de sistematização dos conteúdos linguísticos indicados para esses níveis e de os alunos conhecerem muito pouco os códigos da língua-alvo. Nesse sentido, ao passar a atuar em níveis mais avançados, esse professor começa a perceber que ensinar uma língua vai muito além de ensinar o aluno a falar e a escrever de acordo com a norma padrão e que aprender o maior número de palavras e conjugar "perfeitamente" os verbos da língua-alvo não garante que ele seja capaz de interagir em diferentes situações comunicativas, ou seja, esse professor começa a perceber outros aspectos que envolvem o ensino de uma língua estrangeira.

Ainda, atuar também em diferentes modalidades de ensino pode ser um fator muito importante para o despertar de diferentes perspectivas e abordagens e, portanto, contribuir muito com a formação desses(as) professores(as). Sobre esse aspecto, tanto Europa quanto África, antes de atuarem como bolsistas, respectivamente no NUPEL e no PROEMPLE, realizaram tutorias no PROEMPLE, por meio da disciplina de Estágio I. ${ }^{15}$ Os dados revelaram que essas duas experiências juntas são complementares e foram bastante positivas para a sua formação docente. Para África, as tutorias deram-lhe "uma base de como ensinar para esses alunos estrangeiros".

\footnotetext{
15 A tutoria é uma atividade vinculada à disciplina de Estágio Supervisionado (I e II). Os estudantes dessa disciplina devem planejar atividades para um grupo de, no máximo, 5 alunos de PLE do PROEMPLE. Essas tutorias ocorrem uma vez por semana e duram entre $1 \mathrm{~h} 30$ e $2 \mathrm{~h}$ cada. Esse estudante deve realizar, no mínimo, 10 encontros e apresentar, ao final, um relatório ao professor da disciplina. Segundo Rodrigues (2019, p. 50), esse tipo de avaliação pode mudar a depender do professor que esteja ministrando a disciplina de Estágio.
} 
Vale também pontuar que, em relação à Licenciatura de PLE na UFBA, é nos estágios, por meio das tutorias, que os(as) professores(as) em formação têm maior oportunidade de prática, já que a quantidade de professores(as) em formação selecionados(as) para atuar nos cursos de PLE da UFBA(NUPEL; PROEMPLE) ainda é pequeno. Daí também a importância de uma orientação teórico-pedagógica constante por parte dos(as) professores(as) das disciplinas de estágio supervisionado, a fim de que se formem professores(as) crítico-reflexivos(as), sabedores(as) das concepções, das crenças e das abordagens que orientam a sua prática pedagógica, além da seleção e produção de materiais didáticos e de instrumentos de avaliação, entre outros.

Izaki Gómez (2018) defende, em sua tese, que, para o(a) professor(a) em formação desenvolver a prática reflexiva, é necessário criar oportunidades para que este(a) possa discutir sua prática e a de seus colegas, a partir de aportes teóricos adquiridos e produzidos ao longo da formação acadêmica, tentando desconstruir os sensos comuns e construindo significados sobre o processo de ensino e aprendizagem de modo colaborativo, juntamente com outros(as) professores(as). Ela, ainda, verifica que "o professor em formação necessita de acompanhamento constante e presencial para realizar seu ofício" (IZAKI GÓMEZ, 2018, p. 201).

No entanto, os dados desta pesquisa mostram uma assimetria em relação às diferentes tendências formativas no interior do curso. As falas dos(as) professores(as) em formação revelam que, a depender de quem seja o(a) professor(a) formador(a), haverá ou não elaboração e/ou análise de material didático, de avaliações, de atividades de produção de texto, entre outras coisas, mostrando, desse modo, abordagens individuais 
dos(as) professores(as) formadores(as) no interior do curso que acabam comprometendo significativamente todo o processo formativo em análise. É preciso atentar, portanto, para o fato de que um curso não pode estar tão dependente das diferenças entre as abordagens dos(as) professores(as) formadores(as). A esse respeito, quatro dos cinco tutores só perceberam a carência de orientações sobre planejamento e reflexões teórico-práticas quando, no final da disciplina Estágio Supervisionado I, um(a) dos(as) professores(as) formadores(as) os incentivou a refletir sobre a própria prática e quando começaram a implementar o conjunto de atividades proposto nesta pesquisa. ${ }^{16}$

No relatório entregue a esse(a) professor(a), no final da disciplina, Gabão relata: “[...] Fomos orientados a 'experimentar' e não a dar aulas propriamente ditas. A tutoria foi descrita como um laboratório de ideias para complementar a formação que os aprendizes de português já estavam recebendo no curso tradicional." $\mathrm{Na}$ entrevista, ela relata que os tutores foram orientados, pelo professor formador que iniciou a disciplina, a não usar, por exemplo, materiais do Portal do Professor de Português Língua Estrangeira (PPPLE), pois, para esse professor, seria melhor desenvolver nas tutorias atividades interpessoais, como "passear com os alunos; ajudá-los com estratégias de sobrevivência na cidade"; assim, as tutorias seriam "um sistema de apoio, suporte pros alunos", uma vez que as demais aulas do PROFICI já contemplam atividades como a do PPPLE. ${ }^{17}$ Além disso, também não seria necessário tirar dúvidas dos estudantes, porque eles já têm isso no curso.

\footnotetext{
16 No período em que esta pesquisa foi realizada, a disciplina Estágio Supervisionado I foi ministrada por dois professores formadores, que atuaram em etapas diferentes do curso.

17 O PPPLE é uma plataforma on-line que tem como objetivo central oferecer à comunidade de professores e interessados em geral recursos e materiais pedagógicos para o ensino-aprendizagem-avaliação do português como língua estrangeira. (PPPLE, 2021).
} 
A tutora revela que tentou fazer desse jeito, mas priorizou temas que surgiam durante as aulas, "lacunas que os alunos mostravam na tutoria", no planejamento desses encontros. No decorrer da disciplina de estágio, ela percebeu que não foi imposto nenhum tipo de restrição sobre o que deveria ser feito ou, segundo suas palavras, "como poderíamos atuar como tutores", por esse motivo se sentiu "à vontade para tentar realizar atividades que suprissem as necessidades dos aprendizes" e, a partir do segundo encontro, começou a utilizar unidades didáticas retiradas do Portal do Professor de Português Língua Estrangeira (PPPLE). Gabão ainda menciona que:

Excerto [3]

Gabão: A partir dessa data, passei a iniciar a tutoria sempre pedindo para que os alunos falassem sobre a melhor e a pior parte da semana deles. Desse modo, mesmo sem nos conhecermos muito, passamos a compartilhar um pouco de nossas rotinas e angústias e a criar um espaço de conforto e confiança nas sessões de tutoria. Essa atividade deu, muitas vezes, a oportunidade para que todos participassem dando conselhos e dicas uns aos outros para superar as dificuldades (que nem sempre eram ligadas somente aos estudos). (Relatório de estágio).

Além disso, a tutora declara que pedia sempre aos alunos que explicassem a tarefa ou o projeto da semana (requerido durante as aulas formais do PROFICI) e ajudava-os, dando dicas de lugares para visitarem ou alguma orientação de deslocamento para os locais onde iriam desenvolver os projetos. ${ }^{18}$

18 Segundo Rodrigues (2019 , p. 57), entre fevereiro e julho de 2018, "foram feitos 17 projetos ao longo de 17 semanas, ou seja, um projeto semanal. Os temas eram diversos e buscavam explorar assuntos que pudessem circundar o aluno. Além disso, para cada projeto, o aluno deveria apresentar algum tipo de produto como elaborar um filme, fazer uma apresentação oral, retratar teatralmente suas experiências, entre outras coisas. Esses tipos de tarefas visavam a estimular a criatividade dos alunos, além de aguçar a sua capacidade de criar estratégias diversificadas para resolver os mais variados tipos de problemas, bem como saber interagir com as pessoas na rua". Até 2018, a distribuição das aulas PLE no PROEMPLE era a seguinte: tutoria on-line, curso geral (projetos), reforço, diários, preparatório Celpe-Bras e curso de integração e reflexão cultural e acadêmica. Para mais 
É possível constatar, com base no conjunto de análises realizadas, que a abordagem de ensino de línguas que predominantemente orientava o planejamento das aulas dos professores em formação era a comunicativa (NUNAN Apud BROWN, 1994), visto que fizeram referência a algumas das características dessa abordagem, sobretudo, quando enfatizavam a interação constante com a língua-alvo e quando buscavam relacionar a aprendizagem da linguagem em sala de aula com as situações comunicativas ocorridas fora desse espaço. Entre eles, havia quem se preocupasse com o tratamento dinâmico e criativo do conteúdo da aula, o uso correto da língua-alvo, o desenvolvimento da oralidade, do vocabulário e da escrita, a discussão de temas e de questionamentos que surgem durante a aula, a interação com falantes da língua-alvo (brasileiros(as)).

Ao perguntar aos professores em formação que atuam no PROEMPLE se recebem algum tipo de orientação teóricopedagógica, África é a única que responde positivamente:

Excerto [4]

África: Sempre comunicativa. [...] desde o início,
quando [...] começou as orientações sobre como eu
deveria dar aula, [...] seria sempre comunicativa, é
sempre comunicativa. Então, tem que deixar os alunos
falar o máximo possível, colocar eles sempre em grupo,
em dupla pra que eles falem, pra que eles conversem, pra
que eles possam trocar essas experiências. (Entrevista -
Monitora do PROEMPLE/PROFICI).

Como podemos ver, há, explicitamente, por parte do PROEMPLE, uma orientação acerca da abordagem de ensino de línguas a ser seguida pelos monitores do programa. Por outro lado, de acordo com outros dados da pesquisa, enquanto uma 
parte dos tutores disse não ter recebido orientação na disciplina de Estágio Supervisionado I a esse respeito, a outra parte disse que foi orientanda a desenvolver atividades interpessoais com os alunos. Quanto ao NUPEL, não há uma orientação explícita nesse sentido.

Ainda sobre o Excerto [4], a professora em formação menciona que eles são orientados a separar a turma em pequenos grupos para que possam conversar bastante na língua-alvo. Para África, o ponto positivo disso é que eles acabam se ajudando, "aquele que sabe mais ajuda quem sabe menos"; por outro lado, nota-os conversando em outra língua, geralmente na língua materna deles, por isso precisa controlá-los, "na maior parte do tempo". Além disso, ela comenta que as aulas de projetos são as mais difíceis de ministrar, sobretudo por conta dos conflitos interpessoais que surgem naquele espaço, mas reconhece que o projeto expõe os(as) alunos(as) a situações que os(as) tornam independentes aqui no Brasil. ${ }^{19}$ Vejamos as suas próprias palavras:

Excerto [5]

África: [...] eu percebo que, entre eles, têm uns que não se dá muito com outros, que não gosta de conversar com o outro, de que não gosta de fazer projeto porque, aí, lógico que eles encontram dificuldade de trabalhar em grupo, como eu, como uma pessoa, adulta, madura também tenho dificuldade de trabalhar com meus colegas, eles passam por isso também. [...] Olha, eu acho, eu gosto muito dos projetos, eu acho que os projetos são importantes, eu acho que os projetos tornam esses alunos autônomos, e eles precisam disso, eles tão aqui longe da família, não têm papai, não têm mamãe, então, eles têm que aprender a se virar na vida,

19 Nas aulas de projetos, segundo Rodrigues (2019, p. 59), "nas quartas-feiras, é apresentado o tema, as tarefas e o produto que deve ser entregue, além de uma reflexão escrita a respeito do que eles acharam da experiência, tal relato deve ter no máximo 10 linhas". 
então, eu acho que o projeto é o melhor caminho pra que eles aprendam de forma autônoma, independente, que eles corram atrás, vai lá, pesquisa, então, eu acho que é muito legal o projeto, eu gosto da ideia dos projetos. (Entrevista - Monitora do PROEMPLE/PROFICI).

Retomando o Excerto [3], concluo que a transgressão de Gabão é fruto de sua formação acadêmica. Isso fica claro quando, em outro momento da entrevista, ela comenta que, ao cursar a disciplina LETB 15 - A Avaliação da Proficiência do Falante de Português Língua Estrangeira, estudou os parâmetros de avaliações e as concepções de língua que orientam esse exame e participou de um simulado do Celpe-Bras, o qual foi realizado pela professora que ministrou a segunda etapa da disciplina Estágio Supervisionado I. Assim, segundo ela, todos os alunos puderam conhecer, na prática, as etapas do exame (aplicação e correção das partes oral e escrita). Para Gabão, essa oportunidade de conhecer o exame influenciou bastante a sua prática docente, pois tudo o que selecionou, aplicou, orientou contemplava as diferentes situações comunicativas com as quais eles poderiam se deparar na prova do Celpe-Bras.

América também declara a importância dessa disciplina na sua formação docente. Ela diz que foi a partir dessa disciplina que se expandiu a sua visão, o seu conhecimento:

Excerto [6]

América: [...] Então, a forma com que eu trabalho hoje, que eu aplico avaliação, que eu faço uma atividade, é toda pautada no que eu aprendi naquela disciplina, porque se eu passo uma atividade pro aluno, qual é o objetivo daquela atividade, é matar o tempo da aula, é fazer com que ele fique escrevendo? Não, aquela atividade precisa ter um fundo, ela precisa ter um porquê, um motivo, e tudo isso veio por conta dessa disciplina. (Entrevista Professor em formação do NUPEL). 
Ela revela-nos também que, quando entrou na área de Letras, tinha uma visão muito fechada e limitada da área, mas isso mudou quando conheceu PLE, pois pôde expandir a sua visão e conhecer a área de avaliação, o Celpe-Bras e todas as outras formas de trabalhar com PLE.

É importante observar que essas reflexões acerca do exame não surgiram com os(as) demais professores(as) em formação, mesmo entre aqueles(as) que atuam no Celpe-Bras. Havia, por parte deles(as), preocupação em preparar os alunos para a prova, mas verifico que a visão de proficiência que surge nas entrevistas ou nas observações de aulas, ainda, estava atrelada ao uso correto das unidades da língua, como podemos ver no Excerto [7] a seguir:

Excerto [7]

África: Hoje, por exemplo, teve uma aluna que eu já percebi que já, é, várias vezes, mas eu sempre me esqueço e é pra eu tocar na aula, e eu acabo esquecendo, que é sobre a palavra 'não'. Ela fala 'non', 'non', 'non', mas, resultado, tá lá numa grade de avaliação no CelpeBras como a pessoa fala, né, como a pessoa respondeu às perguntas, como foi a entrevista dela. Tá lá, tem vários tópicos lá. Então, a gente precisa ensinar ao aluno sobre, por onde eles vão passar na prova, que caminho eles têm que percorrer pra poder passar na prova. $\mathrm{O}$ caminho não é só ensinar os gêneros textuais só, somente os gêneros textuais, mas também a forma correta de escrever, a forma correta de falar, é assim que eu penso. (Entrevista - Monitora do PROEMPLE/PROFICI).

Considero, portanto, a disciplina LETB 15 - A Avaliação da Proficiência do Falante de Português Língua Estrangeira, a partir dos relatos expostos pelos(as) professores(as) em formação, muito significativa na formação desses(as) professores(as), visto que não só ressignifica a visão de proficiência deles(as), como 
também ressignifica todos os outros aspectos que envolvem a avaliação, o que enriquece a práxis desses(as) professores(as), como demonstrado por América no Excerto [6].

Isso traz à baila as palavras de Mendes (2008, p. 60), quando diz que o ponto de partida da formação de professores de línguas é auxiliar esses professores "a compreender a sua própria abordagem de ensinar, para que depois possa realimentála e modificá-la a depender das necessidades e características dos contextos nos quais atua". Tal iniciativa, a meu ver, torna a orientação teórico-pedagógica mais significativa, já que os leva "a refletir sobre o que faz e como faz", promove "o necessário diálogo entre teoria e prática, ação e reflexão, conhecimento científico e saber produzido na experiência" (MENDES, 2008, p. 60).

Como se viu nos relatos de Gabão e América, o estudo dos parâmetros de avaliações e das concepções de língua que orientam o Celpe-Bras expandiu a visão de proficiência deles, ressignificou todos os outros aspectos que envolvem a avaliação e, principalmente, impactou positivamente a prática pedagógica desses professores.

Nesse sentido, evidenciou-se, na pesquisa, que um dos papéis dos(as) coordenadores(as)/professores(as) formadores(as) é discutir com os(as) professores(as) em formação as questões/ os conflitos que surgem, bem como incentivar o planejamento das aulas, a produção de materiais didáticos, a reflexão sobre os objetivos, as propostas, os materiais didáticos das aulas e as abordagens de ensino de línguas, a fim de que as aulas de PLE/ PL2 sejam, de fato, um lugar para a interação na língua-alvo e de aprendizagem. 
Ademais, não basta orientar os(as) professores(as) em formação a realizar atividades em grupo, em dupla, para que os(as) seus(suas) alunos(as) interajam, conversem, troquem experiências, sem que isso seja resultado de um planejamento, que considera, por exemplo, o que nos diz África: "têm uns que não se dá muito com outros, que não gosta de conversar com outro [...]". Refletir, portanto, sobre questões como essas e propor ações que contribuíam para a compreensão desses conflitos por todos os envolvidos nesse processo de ensinar e aprender uma LE/L2, que, muitas das vezes, não são só linguísticos, mas também culturais, são ações urgentes em nossas salas de aulas e resultados de uma boa orientação e de um bom planejamento.

Pelo exposto, portanto, percebo que é de suma importância que os(as) professores(as) que hoje estão à frente dessa licenciatura dialoguem com mais frequência sobre o modo como estão conduzindo as disciplinas, para que também não haja assimetrias como estas: professores(as) em formação chegando à disciplina de Estágio Supervisionado I sem ter refletido sobre as concepções de língua, de ensino, de avaliação, que orientam a sua prática, visto que isso dependerá das disciplinas que cursou e com quem, se professor $\mathrm{X}, \mathrm{Y}$ ou $\mathrm{Z}$.

\section{Considerações finais}

Neste estudo, apresentei algumas reflexões acerca da formação inicial de professores(as) de Português como Língua Estrangeira/Segunda Língua (PLE/PL2) da Universidade Federal da Bahia. Procurei evidenciar a importância de uma orientação teórico-pedagógica mais ativa, simétrica (e mais significativa) para os(as) professores(as) em formação, capaz de formar 
professores(as) crítico-reflexivos(as) (e culturalmente sensíveis), a partir dos dados apresentados na pesquisa - intitulada Fiz um blog, e daí? Uma experiência sobre o ensino e a formação inicial de professores de Português como Língua Estrangeira/Segunda Língua em perspectiva intercultural e crítica (CRUZ, 2019) - que teve como participantes da pesquisa professores(as) em formação de Português como Língua Estrangeira/Segunda Língua (PLE/PL2) dessa instituição.

Diante da ausência de uma orientação teórico-pedagógica mais ativa, simétrica (e mais significativa) nesses contextos formativos, o planejamento da aula do(a) professor(a) em formação pode ser prejudicado, visto que, dentre as prioridades dos(as) professores(as) em formação, ao planejarem as aulas, está a demanda dos alunos. É importante pontuar que nem sempre o cumprimento dessa demanda condiz com uma aprendizagem significativa, já que tendências contemporâneas de ensinoaprendizagem de línguas apresentam abordagens/perspectivas que vão de encontro ao ensino tradicional, no qual o ensino da gramática ocupa lugar central. Por isso, é fundamental que os(as) professores(as) em formação sejam (continuamente) preparados(as) para refletirem sobre as concepções que têm orientado a prática docente, pois a ausência de uma orientação em contextos formativos pode também reforçar práticas tradicionais do ensino de línguas.

Pode parecer que me oponho à participação dos(as) alunos(as) na construção do curso, dando, por exemplo, sugestões do que querem aprender. Jamais! Discuto no sentido de chamar a atenção para o que compete ao(à) professor(a): a decisão de como e quando os conteúdos/temas serão trabalhados/abordados no curso, a escolha de instrumentos, procedimentos, abordagens 
que podem contribuir nesse processo de ensino-aprendizagem. Afinal, em um ensino de língua em uma perspectiva intercultural, tal como a defendo (CRUZ, 2019), essa troca enriquece o processo de ensinar e aprender uma língua estrangeira/segunda língua. Mendes afirma que, nessa perspectiva de ensino de língua:

[...] o professor tem papel fundamental, pois é ele que conduz o processo e orienta as experiências de uso da língua desenvolvidas em sala de aula. Ou seja, não só ele é o responsável pelos conteúdos, procedimentos e experiências desenvolvidas pelos alunos com e na língua, mas também pelas relações que se estabelecem entre os sujeitos que interagem na situação de aprendizagem. (MENDES, 2008, p. 59).

Para essa autora, uma formação de professores(as) de línguas adequada, como já mencionei, deve "ajudá-lo a compreender a sua própria abordagem de ensinar, para que depois possa realimentá-la e modificá-la a depender das necessidades e características dos contextos nos quais atua", por isso "qualquer discussão sobre abordagens e procedimentos para o ensino de língua portuguesa, quer em contexto de língua materna ou de estrangeira/segunda língua, deve considerar como elemento fundamental o professor" (MENDES, 2008, p. 59). Além disso, essa demanda precisa ser analisada não apenas pelo(a) professor(a) em formação ou negociada entre o(a) professor(a) em formação e os(as) seus(suas) alunos(as) estrangeiros(as), como temos visto, mas com todos(as) os(as) agentes desse processo (professores(as) formadores(as), professores(as) em formação e estudantes de PLE). Desse modo, estaremos, de fato, preparando os(as) professores(as) para atuar em variados contextos complexos e multilíngues, marcados pela diversidade, 
pela desigualdade e, muitas vezes, pela injustiça social, assim como para decidir, com autonomia e consciência crítica, que representações de língua e de linguagem estarão na base de suas ações.

Os dados revelaram que grande parte dos(as) professores(as) em formação que participaram da pesquisa estava sendo exposta, durante as aulas que ministravam de PLE/PL2, a problemas, situações, conflitos que vão além de aspectos puramente linguísticos, o que infelizmente ainda é natural nas interações entre sujeitos culturalmente diferentes. Esses(as) professores(as) pareciam não estar sendo preparados(as), durante essa formação docente, para problematizar, discutir, refletir sobre os mais variados conflitos que podem surgir nessa interação com o outro, que é o seu aluno, o que tem tido um grande significado no curso de Letras em foco, e uma orientação teórico-pedagógica mais ativa, simétrica (e significativa) não deve depender das abordagens individuais dos(as) professores(as) formadores(as), como demonstraram os dados da pesquisa.

Isso revelou também que, de algum modo, as orientações têm se mostrado superficiais, não têm contribuído satisfatoriamente com a formação docente desses(as) professores(as) em formação, de modo regular e constante, uma vez que isso dependerá do(a) professor(a) formador(a) responsável pela orientação do grupo de alunos. Além disso, como já pontuei, elas não têm dado conta de tratar das questões que surgem durante as aulas de PLE/L2, dos aspectos mais complexos que estão em jogo e das dificuldades enfrentadas por esses(as) professores(as) em formação. 


\section{Referências}

BORTONI-RICARDO, Stella Maris. O professor pesquisador: introdução à pesquisa qualitativa. São Paulo: Parábola, 2008.

BROWN, H. D. Teaching by principles: an interactive approach to language pedagogy. New Jersey: Prentice Hall Regents, 1994.

CANDAU,V.M.Direitoshumanos, educaçãoe interculturalidade: as tensões entre igualdade e diferença. Revista brasileira de educação, v. 13, n. 37, p. 45-56, 2008.

CRUZ, Sara Oliveira da. Fiz um blog, e daí? Uma experiência sobre o ensino e a formação inicial de professores de português como língua estrangeira/segunda língua em perspectiva intercultural e crítica. 2019. 263 f. Dissertação (Mestrado em Língua e Cultura) - Programa de Pós-Graduação em Língua e Cultura, Instituto de Letras, Universidade Federal da Bahia, Salvador, 2019.

DENZIN, N. K.; LINCOLN, Y. S. Introdução: a disciplina e a prática da pesquisa qualitativa. In: DENZIN, N. K.; LINCOLN, Y. S. (org.) DENZIN, N. K.; LINCOLN, Y. S. Planejamento da pesquisa qualitativa: teorias e abordagens. Porto Alegre: Artmed, 2006. p. 15-42.

EGITO, Regina. E no entanto é preciso cantar! Música popular como mediadora do ensino-aprendizagem de Português Língua Estrangeira. 2019. 358 f. Tese (Doutorado em Língua e Cultura) - Programa de Pós-Graduação em Língua e Cultura, Instituto de Letras, Universidade Federal da Bahia, Salvador, 2019.

IZAKI GÓMEZ, Marina Ayumi. Saberes docentes e desafios no ensino de português língua estrangeira na atuação de professores em formação. 2018. 281 f. Tese (Doutorado em Linguística) - Universidade Federal de São Carlos, campus São Carlos, São Carlos, 2018. Disponível em: https://repositorio. ufscar.br/bitstream/handle/ufscar/10133/Tese_Marina\%20 
Ayumi\%20Izaki\%20G\%C3\%B3mez_Vers\%C3\%A3o\%20 BCO.pdf?sequence=1\&isAllowed=y. Acesso em: 15 fev. 2018.

MENDES, Edleise. A Licenciatura em PLE/PL2 na Universidade Federal da Bahia: formando professores para a diversidade. In: SCARAMUCCI, Matilde; BIZON, Ana Cecília C. (org.). Formação inicial e continuada de professores de Português Língua Estrangeira/Segunda Língua no Brasil. 1. ed. Araraquara/SP: Letraria, 2020. v. 1, p. 41-62.

MENDES, Edleise. Aprender a ser e a viver com o outro: materiais didáticos interculturais para o ensino de Português LE/ L2. In: SCHEYERL, D.; SIQUEIRA, S. Materiais didáticos para o ensino de línguas na contemporaneidade: contestações e proposições. Salvador: EDUFBA, 2012a. p. 355-378. Disponível em: https://repositorio.ufba.br/ri/handle/ri/16424. Acesso em: 25 jan. 2021.

MENDES, Edleise. Língua, Cultura e formação de professores: por uma abordagem de ensino intercultural. In: MENDES, E.; CASTRO, M. L. S. (org.). Saberes em português: ensino e formação docente. Campinas: Pontes, 2008. p. 57-77.

MENDES, Edleise. O conceito de língua em perspectiva histórica: reflexos no ensino e na formação de professores de português. In: LOBO, Tânia et all. (org.). ROSAE - Linguística Histórica, História da língua e outras histórias. Salvador-BA: EDUFBA, 2012b. p. 667-678. Disponível em: https://repositorio.ufba.br/ri/ handle/ri/16749. Acesso em: 25 jan. 2021.

MENDES, Edleise. O ensino do português como língua estrangeira (PLE): desafios, tendências contemporâneas e políticas institucionais. In: ANDREEVA, Yana. Horizontes do saber filológico. Sófia-Bulgária: Sveti Klimente Ohridski, 2014. p. 33-45. Disponível em: https://repositorium.sdum.uminho.pt/ bitstream/1822/32287/1/Gramatica\%20verbos\%20Sofia.pdf. Acesso em: 25 jan. 2021. 
MENDES, Edleise. O português como língua de mediação cultural: por uma formação intercultural de professores e alunos de PLE. In: MENDES, E. (org.) Diálogos interculturais: ensino e formação em português língua estrangeira. Campinas, SP: Pontes Editores, 2011. p. 137-158.

NUPEL. Núcleo Permanente de Extensão em Letras. Disponível em: http://www.nupel.ufba.br/apresentacao-eobjetivos. Acesso em: 20 jan. 2021.

PESCE, L.;ABREU, C. B. M. Pesquisa qualitativa: considerações sobre as bases filosóficas e os princípios norteadores. Revista da FAEEBA - Educação e Contemporaneidade, Salvador, v. 22, n. 40, p. 19-29, jul./dez. 2013. Disponível em: https://www. revistas.uneb.br/index.php/faeeba/article/view/747. Acesso em: 13 jan. 2018.

PPPLE. Portal do Professor de Português Língua Estrangeira/ Língua Não Materna. Disponível em: http://www.ppple.org. Acesso em: 15 jan. 2021.

PROFICI. Programa de Proficiência em Língua Estrangeira para Estudantes e Servidores da UFBA. Disponível em: https://profici.ufba.br/. Acesso em: 20 janeiro 2021.

RODRIGUES, Lucas. Uma experiência de aprendizagem com o português LE/L2 na Bahia-Brasil: percepções dos aprendentes pré-PEC-G (UFBA) sobre a pedagogia de projetos. 2019. 151 f. Dissertação ( Mestrado em Língua e Cultura) Universidade Federal da Bahia, Salvador, 2019. 